\title{
1 Extending the Self through the Tools and the Others: a General Framework for Presence and Social Presence in Mediated Interactions
}

\author{
Giuseppe Riva and Fabrizia Mantovani
}

\begin{abstract}
The concept of "presence" originated from and was diffused by a technological scientific community at the same time as the introduction of a unique piece of communication technology, teleoperators: robots controlled from a distance by a human operator. In this case the term telepresence refers to the human operator's sensation of being present in the remote location in which the teleoperator is situated. However, different recent neuropsychology studies suggest that presence has a key role in our cognitive processes: it is the the outcome of an intuitive metacognitive process that allows us to control our actions through the comparison between intentions and perceptions. Specifically, presence has three critical features that cannot be explained by other cognitive processes. First, presence "locates" the Self in an external physical and/or cultural space: the Self is "present" in a space if he/she can act in it. Second, presence provides feedback to the Self about the status of its activity: the Self perceives the variations in presence and tunes its activity accordingly. Third, presence allows the evolution of the Self through the incorporation of tools: tools do not enable us only to extend our reaching space, but when successfully mastered become part of a plastic neural representation of our body that allows their use without further cognitive effort (intuitively). In this way we can focus our cognitive resources on actions that are not only related to the here-and-now, improving the complexity of our goals. The concept of presence concerns the subject and his or her ability to act in the world: I am present in a real or virtual space if I manage to put my intentions into action intuitively. But how does one connect to the Other? How does the Other become present for the subject? The recent discovery of mirror neurons - a class of neurons that are activated both during the execution of purposeful, goal-related actions, and during the observation of similar actions performed by another individual - suggests the existence of a second selective and adaptive mechanism, "social presence", which enables the Self to identify and interact with the Other by understanding his intentions: it is the outcome of an intuitive metacognitive process that allows us to understand the actions of an enacting Other through the comparison between his/her expected intentions and perceptions. In other words, from an evolutionary point of view, social presence has three functions. First, social presence enables the subject to identify the Other and to attribute to him an ontological status - "the other similar to the self" - different from the other objects perceived. Second, social presence allows interaction and communication through the understanding of the Other's intentions. Third, social presence, permits the evolution of the Self through the identification of
\end{abstract}


"optimal shared experiences" (Networked Flow) and the incorporation of artifacts physical and social - linked to them.

Keywords: Presence, Social Presence, Self, Others, Mediated Interaction, Tools

\subsection{Introduction to Chapter 1}

The concept of "presence" originated from and was diffused by a technological scientific community at the same time as the introduction of a unique piece of communication technology, teleoperators: robots controlled from a distance by a human operator (Heeter, 1992). In this case the term telepresence refers to the human operator's sensation of being present in the remote location in which the teleoperator is situated (Held \& Durlach, 1992). But am I present only when I'm experiencing a telepresence system or a virtual reality environment?

Obviously the answer is no. However, many scholars still consider presence as a function of our experience of a given medium (Media Presence). The main result of this approach is one of the most known definitions of presence: the "perceptual illusion of non-mediation" (Lombard \& Ditton, 1997). According to this view, presence in a mediated experience is achieved by means of the disappearance of the medium from the conscious attention of the subject. The main advantage of this definition is its predictive value: the level of presence is reduced by the experience of mediation during the action. So, to improve presence, I have to remove the medium from the attention of the user. The main limitation of this vision is what is not said. Is it a specific cognitive process? What is its role in our daily experience?

In this chapter we will draw on the recent outcomes of cognitive sciences to offer a broader definition of presence, not related to technology only (Waterworth, Waterworth, Mantovani, \& Riva, 2012). For a long time cognitive science considered action, perception, and interpretation as separate activities. A recent trend in cognitive science is instead seeing cognition as embodied: our conceptual system produces dynamically contextualized representations (simulations) that support situated action in different contexts. In this context what is the role of presence?

As we will discuss in the next pages, the experience of presence can be described as the outcome of an intuitive metacognitive process that allows us to control our actions through the comparison between intentions and perceptions (Riva, 2007; Riva \& Mantovani, 2012). Following this view, presence is a core neuropsychological phenomenon whose goal is to produce a sense of agency and control: I am present in a real or virtual space if I manage to put my intentions into action (enacting them).

However, while I can be present, at the same time, someone else can be present to me. This concept is well reflected by the definitions provided by the Merriam Webster dictionary: "presence" is both "the fact or condition of being present" and "the actual person or thing that is present"; "present" is "being in view or at hand" (MerriamWebster, 2010). 
Herewe suggest that to fully understand the concept of presence, weneed toconnect it to its social counterpart: "social presence". A central objective of contemporary cognitive science is the explanation of "Social Cognition", the information-processing system that enables us to engage in social behavior. Specifically, social cognition addresses how people process social information: its encoding, storage, retrieval, and use in social situations.

But what makes a subject "present" within a group? And what happens when the others are not with me physically, such as in a shared virtual worlds?

The recent discovery of "mirror neurons" - a class of neurons that are activated both during the execution of purposeful, goal-related actions, and during the observation of similar actions performed by another individual - suggests the existence of a second selective and adaptive mechanism - "social presence" - which enables the Self to identify and interact with the Other by understanding his intentions. The experience of social presence (that someone else is with me) can be described as the outcome an intuitive metacognitive process that allows us to understand the actions of an enacting Other through the comparison between the expected intentions and the perceived actions.

In the following paragraphs we will endeavor to justify these claims and to underline their relevance for the design and usage of many recent and developing interactive technologies.

\subsection{From Space to Action}

In our daily life the experience of presence is strictly related to space (Spagnolli \& Gamberini, 2005): I'm present in a space.

But how do we experience an external space? Cognitive sciences clearly demonstrated that our spatial experience is the outcome of the interaction of different spatial representations whose integrated activity give rise to spatial awareness (Matelli \& Luppino, 2001). For example, the proprioceptive knowledge of our own body's location in external space (the feeling of being in a given space) requires that information about the angles of each joint be combined with information about the size and shape of the body segments between joints.

Specifically, evidence from clinical and experimental studies indicates that our spatial experience involves the integration of different sensory inputs within two different reference frames (see Figure 1.1) defined by our body model and related to its possibility of action (Longo, Azañón, \& Haggard, 2010; Previc, 1998):

- Egocentric (body as reference of first-person experience). It is based on the body of the observer: it is defined by its three axes: front-back, left-righ, head-feet and within this frame the position of an object changes if the subject moves (Frith \& de Vignemont, 2005). More, this frame defines the "peripersonal space", the 


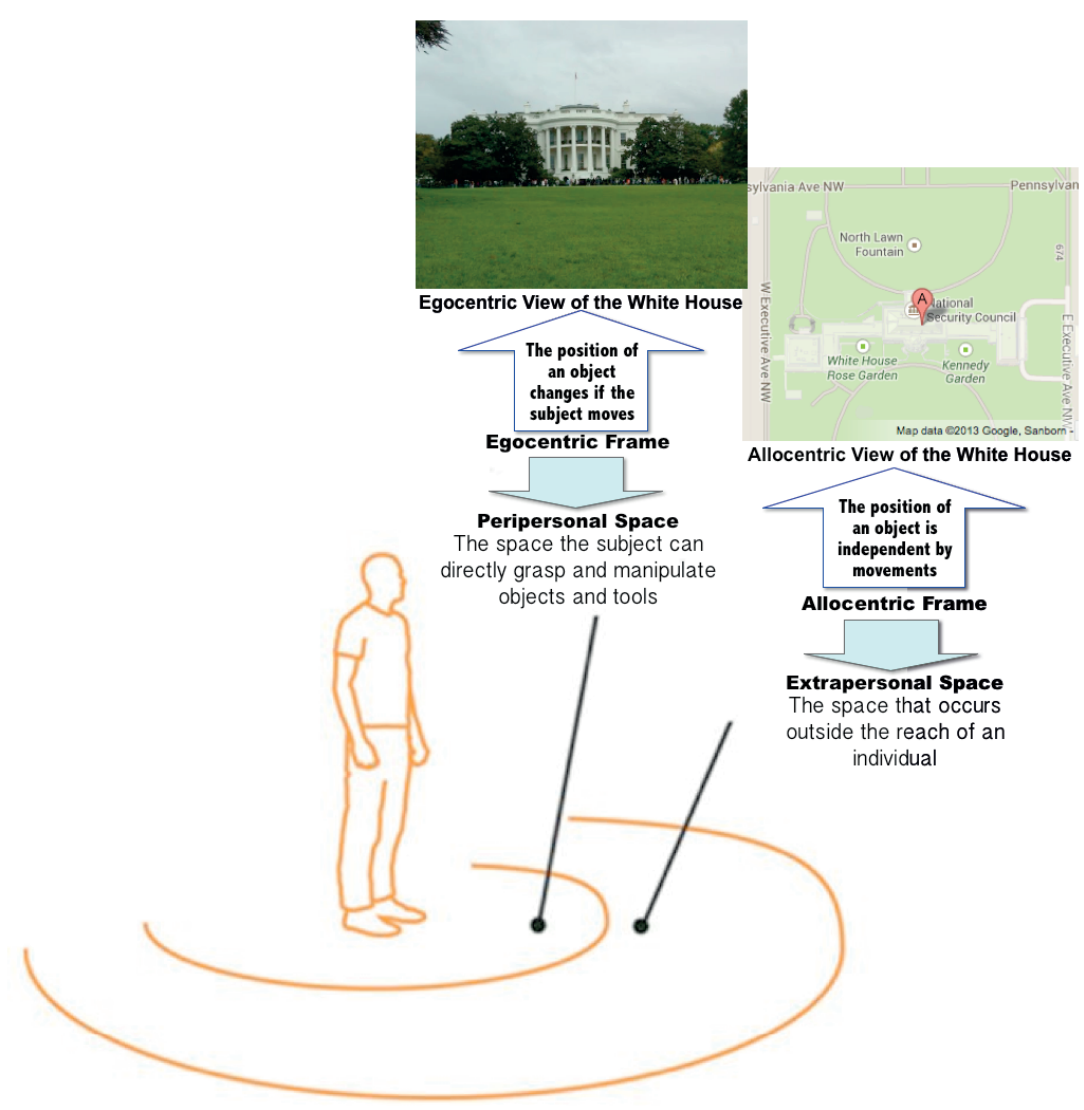

Figure 1.1: The experience of space

space immediately surrounding our bodies. Within this space the subject can directly grasp and manipulate objects and tools.

- Allocentric (body as object in a world). It is defined by the spatial relations between the objects (landmarks) included in it. Within this frame the position of an object does not change if the subject moves, and the object exists even if there is no relation with the self or another person (Frith \& de Vignemont, 2005). It is shaped around the "extrapersonal space", the space that occurs outside the reach of an individual.

This picture suggests that, even if we have a unitary spatial experience, we do not have a single global representation of space. More, we conceive places in terms of the actions we could take towards them: subjects have not a separate knowledge of the place's location relative to them, what they can do in it, and their purposes. An 
example can help in understanding this point. Retrieving an occluded object - e.g. when we lift a box to retrieve a sheet from under it - is an action taken on the basis of a belief about where the object (sheet) is located relative to the self. It follows that to know that the sheet exists when it is covered by the box is a matter of knowing what can be done to make the sheet visible. In other words, spatial perception is a dynamic operation that can be continuously modified and updated by the actions carried out by the subject.

\subsection{From Action to Presence}

According to Gamberini, Spagnolli and Mantovani, the sense of presence is linked to a subject's capacity for action and his ability to position himself within his physical and social space (Spagnolli \& Gamberini, 2005). More precisely, for Spagnolli and Gamberini (2005): "Presence is the feature of the agent which is manifested through the creation of a space during action" (p. 8).

A similar, but broader view, was recently outlined by Riva and Waterworth (Riva, Waterworth, Waterworth, \& Mantovani, 2011; Waterworth, Waterworth, Mantovani, \& Riva, 2010). The idea proposed by these authors is the following: presence can be described as a selective and adaptive mechanism which allows the Self to define the boundaries of action by means of the distinction between "internal" and "external" within the sensory flow.

In other words, from an evolutionary point of view, presence has three functions:

- To check the efficacy of the subject's actions through the comparison of intention and the result of the action. As suggested by the Covert Imitation Theory (Knoblich, Thornton, Grosjean, \& Shiffrar, 2005; Wilson \& Knoblich, 2005), the brain instantiates a sophisticated prereflexive (non-intentional) simulation, based on motor codes, of the outcome of an action and uses it to evaluate its course. From a computational viewpoint, this is achieved through a forward-inverse model:

- First, the agent produces the motor command for achieving a desired state given the current state of the system and the current state of the environment;

- second, an efference copy of the motor command is fed to a forward dynamic model that generates a prediction of the consequences of performing this motor command;

- third, the predicted state is compared with the actual sensory feedback. Errors derived from the difference between the desired state and the actual state can be used to update the model and improve performance.

- To permit the subject to position himself in a space - real, virtual or social through the distinction between "internal" and "external" and the definition of a boundary: the Self is "present" in a space if he/she can act in it. 
- To allow its own evolution through the identification of "optimal experiences" (Flow) and the incorporation of the artifacts - physical and social - linked to it. Artifacts do not enable us only to extend our reaching space, but when successfully mastered become part of a plastic neural representation of our body that allows their use without further cognitive effort (intuitively).

To sum up, we can define presence as the pre-reflexive sensation of "being" in an environment, real or virtual, which results from the capacity to carry out intuitively one's intentions within that environment. But what does it happen when these actions are implemented using a tool?

According to the Merriam Webster dictionary a "tool" is both "a handheld device that aids in accomplishing a task" and "something (as an instrument or apparatus) used in performing an operation" (Merriam-Webster, 2010). These definitions underline that tools are controlled by human action and that they exert an action upon external objects. But, as reflected by the two different definitions, the relationship between the human action, the tool and its final effect is not always the same.

For this reason, in this context we can distinguish between two different types of mediated action (Riva \& Mantovani, 2012): first-order or second-order (see Figure 1.2):

- In first-order mediated actions the subject use the body to control a proximal tool (an artifact present and manipulable in the peripersonal space) to exert an action upon an external object. In practice, there is a direct spatial connection between the body of the subject, the tool and the external object. An example of first-order mediated action is the one of the tennis player striking the ball (external object) with the racquet (proximal tool).

- In second-order mediated action the subject use the body to control a proximal tool that controls a different distal one (a tool present and visible in the extrapersonal space) to exert an action upon an external object. In this situation there is a spatial disconnection between the peripersonal (near) space that contains both the body of the subject and the proximal tool, and the extrapersonal (far) space, that may be either real or virtual, where are located both the distal tool and the external object. An example of second-order mediated action is the one of the cranemen using a lever (proximal tool) to move a mechanical boom (distal tool in the real space) to lift materials (external real objects). Another example, more related to technology, is the one of the videogame player using a joystick (proximal tool) to move an avatar (distal tool in a virtual space) to pick up a sword (external virtual object). A possible, simpler variant of second-order mediated action is the direct use of the body to control a distal tool that exerts an action upon an external object. An example of this variant is the interaction with the Microsoft Kinect system: I move my body to move an avatar (distal tool) to pick up virtual objects.

Here we suggest that these two mediated actions have different effects on our spatial experience (Figure 1.2): 


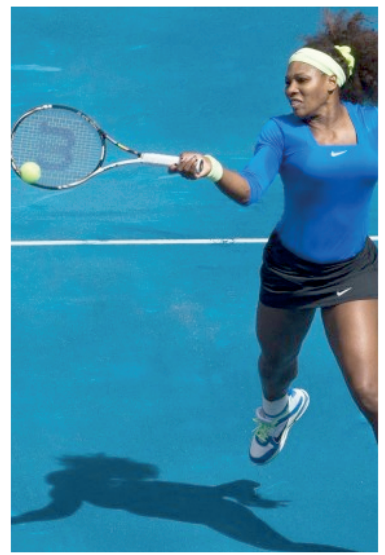

First-order Mediated Action The subject uses the body to control a proximal artifact (the raquet) to achieve his/her intention (striking the ball).

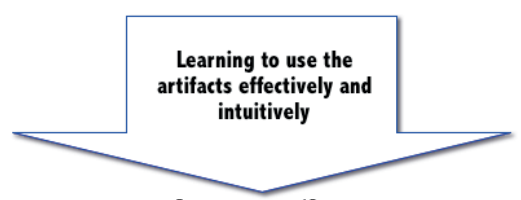

Incorporation

The proximal artifact extends the peripersonal space of the subject

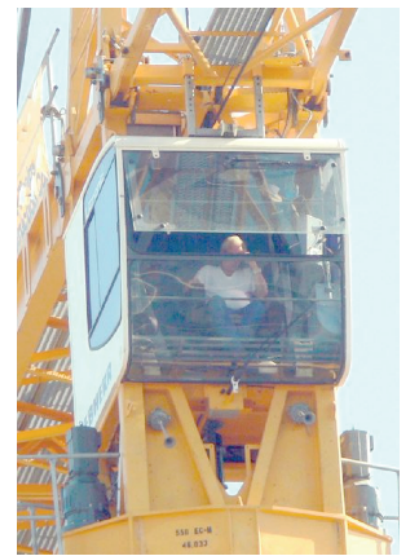

Second-order Mediated Action The subject uses the body to operate a proximal artifact (a lever) that controls a different distal artifact (a mechanical boom) to achieve his/her intention (lifting materials).

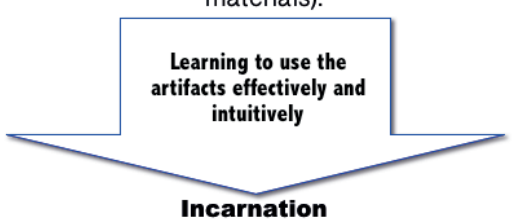

The distal artifact extends the extrapersonal space of the subject

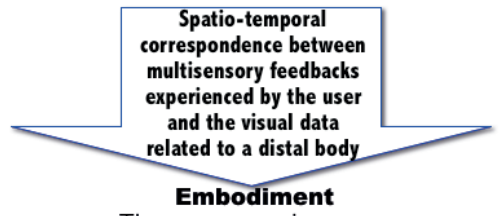

The user experiences a new body in the distal virtual body (avatar)

Figure 1.2: Mediated action and its effects on the experience of the subject

- A successfully learned first-order mediated action produces incorporation: the proximal tool extends the peripersonal space of the subject (the subject is present in the tool);

- a successfully learned second-order mediated action produces incarnation: a second peripersonal space centered on the distal tool (the subject is present in the extrapersonal space - telepresence); 
- a successfully learned second-order mediated action associated to a spatiotemporal correspondence between multisensory feedbacks experienced by the user and the visual data related to the distal virtual body (avatar) produces embodiment: the user experiences a new body in the avatar (the subject is present in a different body - body ownership illusion).

Let's try to deepen these points. Since the seminal work of Atsushi Iriki on macaques and tools (Iriki, Tanaka, \& Iwamura, 1996), many different studies demonstrated that, after a successful training, a proximal tool (first-order mediated action) is incorporated in the bodily experience of the subject (Farnè, Bonifazi, \& Làdavas, 2005; Farné, Serino, \& Làdavas, 2007). From a phenomenological view point, after the training we are now present in the tool and we can use it intuitively as we use our hands and our fingers.

But what does it happen when we learn to use a distal tool (second-order mediated action)? In a different experiment Iriki and colleagues trained macaques to retrieve food by watching their hand/arm movements through a real-time video monitor (Iriki, Tanaka, Obayashi, \& Iwamura, 2001). In other words, in Iriki's study the monkey used the self-image in the monitor as a distal reference of hand movement, similar to when a human is using the Microsoft Kinect. The study showed that the identical neurons, which code the image of the hand in normal condition, responded in a similar manner to the image in the video monitor: here, again, the image of the hand is experienced as a direct an extension of the self. And this happened only after the acquisition of the new motor skill: before training no neuron responded to visual stimuli presented in the monitor screen. This required an integration of the visual data (the distal tool) with the proprioceptive/tactile data (the real hand moving the proximal tool): how are they integrated?

Different authors suggest that a second-order mediated action is based on the simultaneous handling of two different body models - one centered on the real body (based on proprioceptive data) and a second centered on the distal tool (visual data) - that are weighted in a way that minimizes the uncertainty during the mediated action (Jäncke, Cheetham, \& Baumgartner, 2009; Wirth et al., 2007). Specifically, when the distal-centered peripersonal space becomes the prevalent one, it also shifts the extrapersonal space to the one surrounding the distal tool. From an experiential viewpoint the outcome is simple: the subject experiences presence in the distal environment (telepresence).

Recently a series of different studies (Guterstam \& Ehrsson, 2012; Slater, PerezMarcos, Ehrsson, \& Sanchez-Vives, 2009; Slater, Spanlang, Sanchez-Vives, \& Blanke, 2010) using a second-order mediated technology - virtual reality - have demonstrated that it is possible to use it for inducing a body transfer (Embodiment). This is achieved by a spatio-temporal correspondence between multisensory feedbacks experienced by the user and the visual data related to a distal virtual body (avatar). This correspondence may be produced both by the association between touch and 
its visual correlate (seeing the avatar being touched and experiencing the touch simultaneously) and by experiencing the first person perspective of a life-sized virtual human body that appears to substitute the subject's own body. See also Chapters 2 and 4 for a broader discussion of this point.

\subsection{From Presence to Social Presence}

The concept of presence concerns the subject and his or her ability to act in the world: I am present in a real or virtual space if I manage to put my intentions into action with or without the support of tools. But how does the Self connect to the Other? To answer this question we will analyze the implications of the "mirror" neurons discovery which we mentioned at the beginning of the chapter.

These neurons, discovered in the ventral pre-motor cortex of apes (area F5), have, amongst other qualities, that of activating not only when the animal performs a given action, but also when the animal sees another animal - man or ape - performing the same action (Rizzolatti, Fadiga, Gallese, \& Fogassi, 1996; Rizzolatti \& Sinigaglia, 2006). Therefore, the individual who observes is able to put himself in the shoes of the actor: I am able to understand what another is doing because when I watch him I experience, completely intuitively, the same neuron activity as when I perform that action.

The result is the creation of neural representations which are shared on two levels (Gallagher \& Jeannerod, 2002):

- On the one hand, execution and observation share the same neural substratum in one individual subject;

- On the other, when a subject observes another subject's action, the same representations are simultaneously active in the brains of both subjects.

This means that at neural level, the action performed and the action observed are codified in a multi-subjective format, which does not recognize actor or observer. This process is, however, effective if the subject is capable of distinguishing between an action performed and an action perceived. At the moment in which the subject is able, through presence, to distinguish between him or herself and another, "an I and an Other are created". The "Other similar to the Self" thus becomes, together with the Self, one of the two relevant elements which the organism is able to identify within its perceptive flow.

This suggests the existence of a second selective and adaptive mechanism, social presence, which enables the Self to identify and interact with Others by understanding their intentions. In other words, from an evolutionary point of view, social presence has three functions: 
- $\quad$ To enable the subject to identify the Other and to attribute to him an ontological status - "the Other similar to the Self" - different from the other objects perceived,

- To allow interaction and communication through the understanding of the Other's intentions; from the computational viewpoint, it happens using the same approach used by Presence:

- First, the agent recognizes a motor intention, and identify the actor as another intentional self (Other);

- second, an efference copy of the motor command is fed to a forward dynamic model that generates a prediction of the consequences of performing this motor command (goal);

- third, the predicted state is compared with the actual sensory feedback. Errors derived from the difference between the predicted state and the actual state (break) can be used to update the model and improve performance.

- $\quad$ To permit the evolution of the Self through the identification of "optimal shared experiences" (Networked Flow) and the incorporation of artifacts - physical and social - linked to them.

In summary, we can define social presence (Biocca, Harms, \& Burgoon, 2003; Riva, 2008; Riva, Davide, \& IJsselsteijn, 2003) as the sensation of "being with other selves" in a real or virtual environment, resulting from the ability to intuitively recognize Others'intentions in our surroundings (see also Chapters 5 and 6, this volume).

From the combined analysis of presence and social presence, it emerges that the point of contact between these two processes clearly lies in the intentions and their codification by means of motor representations of action (Knoblich \& Flach, 2003):

- On the one hand, presence verifies the effective fulfillment (enaction) of the intention in action;

- On the other hand social presence permits the identification of the Other's intentions through the analysis of his/her actions.

But how do we structure and manage intentions? An important attempt to explain the structure of intentions has been made by the French researcher Elisabeth Pacherie (2008). The main assumptions of this model, known as the "dynamic theory of intentions" are the following:

- It does not make sense to consider an action as an individual mental act. Intentions are a dynamic structure arranged on a number of levels.

- This organization is hierarchically structured on three mutually inclusive levels:

- Motor intentions (M-intentions);

- Proximal intentions, situated in the present (P-intentions);

- Distal intentions, directed towards the future (D-intentions).

- The relationship between these levels is one of inclusion and organization. Specifically, a distal intention (to build a house) is composed of a series of proximal 
intentions (to lay the foundations, build the walls), which are themselves made up of a series of motor intentions.

\subsection{The Evolutionary Role of Presence and Social Presence}

In his book, “Descartes' Error: Emotion, Reason, and the Human Brain”, the neuropsychologist Antonio Damasio identifies the sense of the self as the essential nucleus of the conscious, the result of both interaction and the relationships between the organism and the object (Damasio, 1994).

The origin of the sense of the self lies in the "proto-self" (Damasio, 1994), "a coherent collection of neural patterns which map second by second the state of the physical structure of the organism in its various dimensions” (p. 189). The proto-self's main task, of which the subject is not aware, is "positionality", that is, to identify organism's physical boundaries by verifying somatic functions.

Through the evolution of the proto-self, two other types of self successively emerge - the "core self" and the "autobiographical self "- which are at the basis of conscious experience. The core self can be described as a conscious representation of the present in which there are three elements: the object of which the subject is aware, the position of the subject's own body in relation to that object, and the relationship which is established between the two.

The transition from the core self to the autobiographical self is made possible through the use of language. By using language we can create a story, our story, in which we position and structure the different experiences which we have had. It is through the development and awareness of this story that the self becomes selfconscious, aware of itself.

Starting from this view, the hypothesis discussed here is that each level of the Self is associated to a specific ability to differentiate between internal and external which increases the control that the organism has over its own activities, thus increasing its chances of survival (Riva, 2009; Riva, Waterworth, \& Waterworth, 2004; Riva et al., 2011). Furthermore, the close link between the levels of the Self and the three intentional levels described by the Dynamic Theory of Intentions presented by Pacherie $(2006,2008)$ enables us to associate each level to a specific intentional capacity and a level of presence and social presence (see Table 1.1 for a summary of the presented model). 
Table 1.1: The presence model

\begin{tabular}{|c|c|}
\hline Concept & Definition \\
\hline Presence & $\begin{array}{l}\text { A selective and adaptive mechanism which allows the Self to define the } \\
\text { boundaries of action by means of the distinction between "internal" and } \\
\text { "external" within the sensory flow. The feeling of presence is the outcome } \\
\text { an intuitive metacognitive process that allows us to control our actions } \\
\text { through the comparison between intentions and perceptions. Although } \\
\text { presence is a unitary feeling, on the process side it can be divided into } \\
\text { three different layers/subprocesses, phylogenetically different, and } \\
\text { strictly related to the evolution of self. }\end{array}$ \\
\hline Proto Presence & $\begin{array}{l}\text { The first subprocess of Presence is related to the emergence of proto-self: } \\
\text { the intuitive perception of successfully differentiating the self from the } \\
\text { external world through action. It depends on the level of perception-action } \\
\text { coupling (Self vs. non Self). }\end{array}$ \\
\hline Core Presence & $\begin{array}{l}\text { The second subprocess of Presence is related to the emergence of core- } \\
\text { self: the intuitive perception of successfully acting in the external world } \\
\text { towards a present Object. It depends on the level of vividness (Self vs. } \\
\text { Present External World). }\end{array}$ \\
\hline Extended Presence & $\begin{array}{l}\text { The third subprocess of Presence is related to the emergence of extended- } \\
\text { self: the intuitive perception of successfully acting in the external world } \\
\text { towards a possible Object. It depends on the level of relevance (Self vs. } \\
\text { Possible External World). }\end{array}$ \\
\hline Object & $\begin{array}{l}\text { The person, condition, thing, or event at which an action is directed. An } \\
\text { Object is a psychological representation, and therefore actions can be } \\
\text { directed either at objects of the world (present Objects) or fictions, the } \\
\text { future, and other forms of virtuality (possible Objects). }\end{array}$ \\
\hline Social Presence & $\begin{array}{l}\text { A selective and adaptive mechanism which allows the Self to identify } \\
\text { and interact with Others by understanding their intentions. The feeling of } \\
\text { social presence is the the outcome of an intuitive metacognitive process } \\
\text { that allows us to understand the actions of an enacting Other through } \\
\text { the comparison between his/her expected intentions and perceptions. } \\
\text { Although social presence is a unitary feeling, on the process side it can } \\
\text { be divided into three different layers/subprocesses, phylogenetically } \\
\text { different, and strictly related to the evolution of self. }\end{array}$ \\
\hline Other's Presence & $\begin{array}{l}\text { The first subprocess of Social Presence is related to the ability of } \\
\text { recognizing motor intentions in other individuals. This capacity allows the } \\
\text { Self to recognize an intentional Other (the Other in opposition to the Self). }\end{array}$ \\
\hline Interactive Presence & $\begin{array}{l}\text { The second subprocess of Social Presence is related to the ability of } \\
\text { recognizing motor and proximal intentions in other individuals. This } \\
\text { capacity allows the Self to identify the Other whose intention is directed } \\
\text { towards him (the Other towards the Self). }\end{array}$ \\
\hline
\end{tabular}


Table 1.1: The presence model

\begin{tabular}{ll}
\hline Concept & Definition \\
\hline Shared Presence & $\begin{array}{l}\text { The third subprocess of Social Presence is related to the ability of } \\
\text { recognizing motor, proximal and distal intentions in other individuals. This } \\
\text { capacity allows the Self to identify Another whose intentions correspond } \\
\text { to his/her own. (the Other like the Self). }\end{array}$ \\
\hline Optimal & $\begin{array}{l}\text { Specific individual (Flow) and social (Networked Flow) situations in which } \\
\text { the individual experiences the maximum feeling of presence. }\end{array}$ \\
\hline Flow & $\begin{array}{l}\text { There are exceptional situations - e.g., a tennis player who goes to the } \\
\text { right (proto presence) before the ball bounces on the court to swing a } \\
\text { winning forehand ground stroke (core presence) on a second set-point } \\
\text { at the Wimbledon final (extended presence) - in which the activity of } \\
\text { the subject is characterized by a high level of presence in all the three } \\
\text { different subprocesses (Maximal Presence). When this experience is } \\
\text { associated with a positive emotional state, it constitutes a flow state. }\end{array}$ \\
$\begin{array}{l}\text { There are exceptional social situations in which a group of subjects in } \\
\text { a liminality phase (a state of transition, in which the earlier positive } \\
\text { condition is no longer present, and the future positive condition has not } \\
\text { yet come into) experiences the maximum level of social presence (the } \\
\text { feeling of sharing objectives and emotions with others) and the feeling } \\
\text { of being able through the their collective action of exiting from liminality } \\
\text { (maximum level of presence). }\end{array}$ \\
\hline Networked Flow
\end{tabular}

\subsubsection{The Three Levels of Presence}

Even if Presence is a unitary feeling, the recent neuropsychological research has shown that, on the process side, it can be divided in three different layers/subprocesses phylogenetically different, and strictly related to the evolution of Self:

- Proto Presence (Self vs. non Self - M-Intentions);

- Core Presence (Self vs. present external world - P-Intentions);

- Extended Presence (Self vs. possible/future worlds - D-Intentions).

In sum, presence allows the Self to evolve by extending the boundaries of its actions through the acquisition higher levels of intentional ability.

The first level of the self, the proto-self, corresponds to "proto presence" (proprioceptive), the ability to enact motor intentions by moving the body (the boundaries of the Self's actions are determined by the body). This is made possible by the Self's ability to distinguish between internal and external states. This happens through perception-action coupling: the more the organism is able to correctly associate stimuli to movement in sensorial flow, the better it is able to differentiate itself from its 
external surroundings and thus increase its chances of survival (the Self as opposed to the not-Self).

The second level of the self - the core self - corresponds to "core presence" (perceptual), the ability to enact proximal intentions through the identification of direct affordances (the boundaries of the Self's actions are determined by the perceived world). This is made possible by the Self's ability to separate and couple representations and perceptions, picking out those which are relevant. Within the experiential flow, the Self separates intentional information from the real object. The better the organism is able to distinguish between imagination and perception, planning and action, the greater its chances of survival will be.

However, the organism must also be able to analyze and identify the perceptions which correspond to the intentional information (relevance). The more the organism is able to successfully connect intentional information to real-world objects, the greater the likelihood of fulfilling its proximal intentions and thus the greater its chances of survival (the Self in relation to the present world). In general, there are two elements which allow this distinction to be made: vividity and multi-sensoriality. In fact, mental images are much less vivid than perceptions, and are also characterized by the predominant visual component. Coupling, on the other hand, takes place thanks to recognizability: the capacity to associate a real object to a given intention.

The third level of the self - the autobiographical self - corresponds to "extended presence" (reflective), the ability to enact distal intentions through the identification of indirect affordances. This is made possible thanks to the Self's ability to analyze representations and identify those which are relevant. The better the organism is able to separate itself from the present and identify within its own representations those most relevant, the greater are its chances of survival (the boundaries of the Self's are determined by possible/conceivable worlds).

Extended presence is also the element which allows for the subject's "absence", that is, its presence in an exclusively mental activity. During an experience of absence, such as thinking, day-dreaming or meditating, the subject tries to separate itself as much as possible from the outside world and to concentrate exclusively on its own mental processes (the self outside of its external surroundings). In general, the more the subject believes that mental activity is important for its "internality", the greater its attempts will be to isolate itself from the outside world.

What is the link between the three levels of presence? They are evolutionarily organized - from the lowest to the highest - but functionally separate. This means that, in the case of injuries which may impair the subject's ability to activate one of the three levels, the others will still be functional. For example, in the case of a neurological disorder called autotopagnosia - the inability to localize parts of the body - the subject loses its proto presence. This does not prevent the subject from continuing to experience core presence and extended presence.

The three levels of presence are linked by their simultaneous influence on the actions of the subject: the experience of the action changes according to the presence of 
the subject on each of the three levels. It is important to note that the subject is usually unaware of the role of the three levels of presence in determining the characteristics of his or her actions. However, the subject is evolutionarily programmed to consciously understand the variations between the three levels and if necessary, to modify an action in order to return to its initial state. If, during a virtual reality experience, my arm moves and suddenly comes into contact with a cable, I immediately become aware of the change at the level of proto presence and I shift my attention from my virtual reality experience to the cable which is impeding my movement (Spagnolli \& Gamberini, 2002)

The same is true for the other levels. If the reality TV show the subject is watching becomes boring or upsetting, the subject becomes immediately aware of the variation in the level of extended presence, and can decide whether or not to pick up the remote control and change channel.

\subsubsection{The Three Levels of Social Presence}

The study of infants and the analysis of their ability of understanding and interacting with people (Meltzoff \& Decety, 2003) suggest that also Social Presence, on the process side, includes three different layers/subprocesses phylogenetically different, but mutually inclusive (Riva, 2008):

- Other's Presence (Other vs the Self - M-Intentions);

- Interactive Presence (Other toward the Self - P-Intentions);

- Shared Presence (Other is like the Self - D-Intentions).

The first level of imitative skills - the ability to imitate a human being - corresponds to "Other's Presence", the ability to recognize motor intentions, which allows the Self to recognize an intentional Other: the better the subject is able to recognize within the sensorial flow the stimuli which relate to "another similar to the self", the better he is able to carry out an intention, and thus increas his chances of survival (the Other in opposition to the Self).

The second level of imitative skills - the ability to identify a human being who is imitating me - corresponds to "Interactive Presence", the ability to recognize motor and proximal intentions which allows the Self to identify the Other whose intention is directed towards him: the better the subject is able to recognize within the sensorial flow the intention direct towards him by "an Other similar to the self", the greater the chances of successfully carrying out an action, and therefore the greater the chances of survival (the Other towards the Self).

The third level of imitative skills - the ability to recognize the intentions and emotions of a human being - corresponds to "Shared Presence", the ability to recognize motor, proximal and distal intentions, which enables the Self to identify Another whose intentions correspond to his own: the better the subject is able to recognize 
within the sensorial flow an "Other similar to the self" with intentions the same as his own, the better he will be able to successfully initiate collaborative interaction or communication, increasing his chances of survival (the Other like the Self).

Shared presence permits the subject to feel empathy, the capacity to see oneself in another person, to get inside another's thoughts and state of mind. During the experience of empathy, the subject separates himself from his own intentional and emotional state, and identifies with that of another person (the Other merges with the Self).

What is the link between the three levels of social presence? As with presence, the three levels are evolutionarily organized: from the lowest to the highest. However, unlike presence, the levels of social presence are not functionally separate but mutually inclusive. This leads to two consequences. The superior levels also include the inferior levels: if the subject is able to understand distal intentions (shared presence), he is also capable of understanding motor intentions (other's presence). At the same time, it is impossible to activate the higher levels of social presence if the lower levels are not activated first: if I am unable to understand a subject's proximal intentions (interactive presence) then I will not be able to understand his distal intentions (shared presence).

The three levels of social presence are linked by simultaneous influences on the subject's capacity for social interaction: the way in which the interaction is experienced changes depending on the level of social presence experienced by the subject. It is important to note that, as with presence, the subject is unaware of the role of social presence in determining the characteristics of his actions. He is, however, evolutionarily programmed to perceive the shift from one level of social presence to another in social interactions. Furthermore, if this shift offers a valuable opportunity, the subject can act to increase his level of social presence. If a girl starts staring at me at a party, I immediately become aware of the shift from other's presence (the girl is at the same party as me) to interactive presence (the girl is looking at me). If the girl is interesting, I can approach her and talk to her in order to understand her intentions: is she looking at me because she likes me or because I have a stain on my jacket?

\subsection{From Theory to Practice: the Development of Better Interactive Technologies}

At this point, a possible comment from the readers of the chapter is this one: interesting stuff, but how can it help me in developing better interactive technologies?

The first deductions which can be made from what has thus far been discussed, is the existence of link between presence and the effectiveness of an action: the greater level of presence a subject experiences in an activity, the greater the organism's involvement in the activity will be, and this increases the probability of the activity ending well (the transformation of the intention into action). 
This concept is particularly important when the subject carries out the activity by using a tool, including media. The use of a tool compels the subject to modify his action, forcing him to adapt himself to the tool. In this case, given equal conditions and skills, the greater efficacy of the activity when carried out using a tool is linked to the tool's ability to facilitate the subject in increasing his level of presence. We shall give an example to explain this concept.

Imagine that we have a computer and have to copy a file from a disc onto a USB stick. We have seen that proto presence constitutes the first level of presence, which concerns the level of coupling between movement and perception. This means that an activity in which it is easy to immediately identify the result of one's own movements is preferable to an activity in which this is not possible. For this reason, the subject, all things being equal, will tend to choose a program which facilitates the direct perception of movement - I move the file by dragging it with the mouse - as opposed to one which does not - the instruction "copy name-of-file a: b:". Likewise, using the arrow key on the keyboard to copy the file is preferable to using an instruction, but worse than using the mouse.

During an activity we are obviously not influenced by only one level of presence, but by all three levels together. For example, when we are doing a distance-learning training course, interaction with the mouse is preferred to interaction with the keyboard (proto presence); the use of multimedia equipment is better than making use of a simple text (core presence); undertaking tasks linked to experience and to the interests of the project is preferable to carrying out abstract tasks (extended presence).

But what happens when we have to choose between activities or artifacts which differ within the different levels of presence? For example, how do users choose between a distance-learning training course with interesting modules but which uses only texts, and another which makes extensive use of multimedia but which addresses less interesting topics? In these situations, the level of presence which is evolutionarily superior prevails: first extended presence, followed by core and then proto presence. Users will therefore choose the course featuring interesting topics but which only uses text.

A second consequence of the considerations made in the preceding paragraphs, is the existence of certain "optimal experiences", in which the individual experiences the maximum feeling of presence at each of the three levels. This experience, when it is associated with a positive emotional state (it is also possible to experience the maximum feeling of presence in emotionally negative situations, such as during an escape) is defined as "flow experience" (Csikszentmihalyi, 1990, 1994). This state is characterized by a high level of concentration and participation in the activity, by the balance of the perception of the difficulties of the situation and the challenge, and personal skills, by the distortion of the sense of time (the internal clock slows down, whilst the external one speeds up), and by a natural interest in the process 
which produces a sense of pleasure and satisfaction. More, flow has been associated to creativity and emotional wellbeing (Csikszentmihalyi, 1997).

In our model, optimal presence in a mediated experience arises from an optimal combination of form and content, able to support the activity of the user. At the higher level of activity, optimal presence arises when the contents of extended consciousness are aligned with the other layers of the self, and attention is directed to a currently present external world (Waterworth \& Waterworth, 2006). However, this is a difficult task to achieve for a developer. He/She has to provide as much immersion as possible, integrating proto (spatial) and core (sensory) presence. To integrate extended presence, the events and entities experienced in the interactive system must have significance for the participant. The form must provide the means for a convincing bodily and perceptual illusion, but the content should be integrated with (and so attract attention to) the form for the illusion of mediated presence to happen convincingly.

Similar considerations can also be made concerning the concept of social presence.

First, there is a link between presence and efficacy of interaction: the more often that the organism experiences a high level of social presence during interaction, the greater his ability to understand the other, and therefore the chances of the interaction being successful increase.

Second, there is also a specific optimal experience for social presence - "networked flow" - the result of the association between (Gaggioli, Milani, Mazzoni, \& Riva, 2011, 2013):

- The maximum level of social presence: the feeling of sharing objectives and emotions with others;

- The group members' perception of being in a phase of liminality: a state of transition, of being "about to...", in which the earlier positive condition is no longer present, and the future positive condition has not yet come into being.

- The shared recognition of a possible common strategy for exiting from liminality: everybody working towards a shared objective, which the group can change.

- The maximum level of presence: the feeling of being able, through the personal involvement in the group, of successfully transforming intentions - both individual and collective - in actions.

In this case, the maximum level of presence and social presence permits the subject to increase their self-efficacy and to find the motivation for change within the shared group activity.

This concept shares a number of similarities with the concept of the "nascent state" proposed by Alberoni. Subjects who go through this have a strange experience which causes them to develop an alternative interpretation of existence (Alberoni, 1977). "Nascent state is an exploration of the boundaries of the possible, given a certain type of social system, with the goal of maximizing what is realizable within that experience 
and solidarity for oneself and others in that moment in time. The group of men amongst whom a nascent state is created will always attempt to construct a way of living which is completely different from the everyday institutional norm" ( $p .31)$. Alberoni's ideas highlight how the simultaneous union between high levels of presence and social presence make networked flow a state of transition which constitutes the specific conditions for social transformation. It is at this moment that the subjective intention becomes collective (we-intention).

This model provides relevant guidelines also to developers of collaborative mediated experiences (Graffigna, Barello, \& Riva, 2013a; Riva, Banos, Botella, Wiederhold, \& Gaggioli, 2012):

First, the more the communicative task is complex, the more are the intentional levels that have to be supported by the mediated experience to induce a high level of presence: it is difficult to induce social presence during complex cooperative tasks.

Second, the best avatars are those whom can express fully the intentions of the user: it is not critical to have a human-like avatar. Is more important to have the possibility to express intentions through them. According to communication and cognitive psychology, nonverbal cues (facial expressions and body movements) are critical to provide intentional cues.

Finally, we have the highest level of Social Presence when the environment is able to support the full intentional chain of the Other: if the Other is not able to express and enact fully his/her intentions through the medium the level of Social Presence will be low.

In conclusion the model offers us two general guidelines for developing optimal presence in a mediated interactive/collaborative experience:

- To induce optimal presence, a mediated experience has to include/support recognition of the specific purposes of the users. If the experience or the subjects involved are not able to identify the specific objectives of all the users they will fail in supporting his/her action, reducing the level of presence.

- To induce optimal presence, a mediated experience has to identify and support the specific tools that mediate the activity of the users. Most of the activity of the users is mediated by physical and social artifacts. The experience has to identify and embed in the system features to support the individual and shared actions of the users effectively.

Another important consequence of this model is that we can develop technologies "Positive Technologies" - that areable to improve the quality of our personal experience by enhancing the level of presence and social presence experienced interacting with them (Graffigna, Barello, \& Riva, 2013b; Graffigna, Barello, Wiederhold, Bosio, \& Riva, 2013; Riva, 2012). Specifically, presence can be used to manipulate the features of an interactive experience in three separate but related ways (Graffigna, Barello, et al., 2013a; Riva et al., 2012):

- By structuring it using a goal, rules and a feedback system - Extended Presence and Shared Presence (McGonigal, 2011). The goal provides subjects with a sense of 
purpose focusing attention and orienting his/her participation in the experience. The rules, by removing or limiting the obvious ways of getting to the goal, push subjects to see the experience in a different way. The feedback system tells players how close they are to achieving the goal and provides motivation to keep trying.

- By augmenting it to achieve multimodal and mixed experiences - Core Presence. Technology allows multisensory experiences in which content and its interaction is offered through more than one of the senses. It is even possible to use technology to overlay virtual objects onto real scenes (Rosenblum, 2000).

- By replacing it with a synthetic one - Proto Presence. Using VR it is possible to simulate physical presence in a synthetic world that reacts to the action of the subject as if he/she was really there. More, the replacement possibilities offered by technology even extend to the induction of an illusion of ownership over a virtual arm or a virtual body (Slater et al., 2010).

\subsection{Conclusion to Chapter 1}

The chapter presented the experience of presence and social presence as two neuropsychological phenomena, evolved from the interplay of our biological and cultural inheritance, whose goal is the enaction of the volition of the Self (Presence) and the understanding of the volition of the Other (Social Presence):

- "Presence" is defined as the non-mediated (intutive) perception of successfully transforming intentions in action (enaction) within an external world;

- "Social Presence” is defined as the intuitve perception of an intentional Other (I can recognize his/her intentions) within an external world.

Both Presence and Social Presence evolve in time, and their evolution is strictly related to the three-stage model of the ontogenesis of Self introduced by Damasio (Proto-Self, Core Self, Autobiographical Self). More, we can identify higher levels of Presence and Social Presence associated to higher levels of intentional granularity: the more is the complexity of the expressed and recognized intentions, the more is the level of Presence and Social Presence experienced by the Self.

How does this vision can help the development of effective interactive technologies? Here we suggested that the experience of the highest level of presence and social presence is associated to specific optimal experiences - flow and networked flow that allow better individual and social activities. This suggests the development of optimal technologies - "Positive Technologies" - that are able to improve the quality of our personal experience by enhancing the level of presence and social presence experienced interacting with them.

Obviously, this chapter has its limitations: the framework here introduced is still in progress and some of the claims presented require additional theoretical work and an empirical confirmation. Nevertheless, quite independently of the intricacies 
of terminology and conceptualizations, we hope that the Presence framework discussed in these pages will help to disentangle the variety of claims and theories that characterizes interactivity and intersubjectivity research.

\section{References}

Biocca, F., Harms, C., \& Burgoon, J.K. (2003). Toward a more robust theory and measure of social presence: Review and suggested criteria. Presence: Teleoperators, and Virtual Environments, 12(5), 456-480.

Csikszentmihalyi, M. (1990). Flow: The psychology of optimal experience. New York: HarperCollins.

Csikszentmihalyi, M. (1994). The evolving self. New York: Harper Perennial.

Csikszentmihalyi, M. (1997). Creativity: Flow and the Psychology of Discovery and Invention. New York: Harper Perennial.

Damasio, A. (1994). Decartes' error: Emotion, reason, and the brain. New York: Grosset/Putnam.

Farnè, A., Bonifazi, S., \& Làdavas, E. (2005). The role played by tool-use and tool-length on the Plastic Elongation of peri-hand space: a single case study Cognitive Neuropsychology, 22(3-4), 408-418.

Farné, A., Serino, A., \& Làdavas, E. (2007). Dynamic size-change of perihand space following tooluse: Determinants and spatial characteristics revealed through cross-modal extinction. Cortex, 43, 436-443.

Frith, U., \& de Vignemont, F. (2005). Egocentrism, allocentrism, and Asperger syndrome. Consciousness and cognition, 14(4), 719-738.

Gaggioli, A., Milani, L., Mazzoni, E., \& Riva, G. (2011). Networked Flow: A Framework for Understanding the Dynamics of Creative Collaboration in Educational and Training Settings. The Open Education Journal, 4(Suppl 2:M2), 107-115.

Gaggioli, A., Milani, L., Mazzoni, E., \& Riva, G. (2013). Networked Flow: Towards an Understanding of Creative Networks. Dordrecht: Springer.

Gallagher, R., \& Jeannerod, M. (2002). From action to interaction. Journal of Consciousness Studies, 9, 3-26.

Graffigna, G., Barello, S., \& Riva, G. (2013a). How to make health information technology effective: the challenge of patient engagement. Archives of physical medicine and rehabilitation, 94(10), 2034-2035.

Graffigna, G., Barello, S., \& Riva, G. (2013b). Technologies for patient engagement. Health affairs, 32(6), 1172.

Graffigna, G., Barello, S., Wiederhold, B. K., Bosio, A. C., \& Riva, G. (2013). Positive technology as a driver for health engagement. Stud Health Technol Inform, 191, 9-17.

Guterstam, A., \& Ehrsson, H. H. (2012). Disowning one's seen real body during an out-of-body illusion. Consciousness and cognition, 21(2), 1037-1042.

Heeter, C. (1992). Being There: The subjective experience of presence. Presence: Teleoperators and Virtual Environments, 1(2), 262-271.

Held, R.M., \& Durlach, N.I. (1992). Telepresence. Presence, Teleoperators, and Virtual Environments, 1(1), 109-112.

Iriki, A., Tanaka, M., \& Iwamura, Y. (1996). Coding of modified body schema during tool use by macaque postcentral neurones. Neuroreport, 7(14), 2325-2330.

Iriki, A., Tanaka, M., Obayashi, S., \& Iwamura, Y. (2001). Self-images in the video monitor coded by monkey intraparietal neurons. Neuroscience Research, 40(2), 163-173.

Jäncke, L., Cheetham, M:, \& Baumgartner, T. (2009). Virtual Reality and the Role of the Prefrontal Cortex in Adults and Children. Front Neurosci, 3(1), 52-59. 
Knoblich, G., \& Flach, R. (2003). Action identity: Evidence from self-recognition, prediction, and coordination. Consciousness and cognition, 12, 620-632.

Knoblich, G., Thornton, I., Grosjean, M., \& Shiffrar, M. (Eds.). (2005). Human Body Perception from the Inside Out. New York: Oxford University Press.

Lombard, M., \& Ditton, T. (1997). At the heart of it all: The concept of presence. Journal of Computer Mediated-Communication [On-line], 3(2), Available: http://www.ascusc.org/jcmc/vol3/issue2/ lombard.html.

Longo, M.R., Azañón, L., \& Haggard, P. (2010). More than skin deep: Body representation beyond primary somatosensory cortex. Neuropsychologia, 48, 655-668.

Matelli, M., \& Luppino, G. (2001). Parietofrontal circuits for action and space perception in the macaque monkey. Neuroimage, 14(1 Pt 2), S27-32.

McGonigal, J. (2011). Reality Is Broken. Why games make us better and how they can change the world. New York: The Penguin Press.

Meltzoff, A.N., \& Decety, J. (2003). What imitation tells us about social cognition: a rapprochement between developmental psychology and cognitive neuroscience. Philosophical Transactions of the Royal Society, 358, 491-500.

Merriam-Webster. (2010). The Merriam-Webster Dictionary. Springfield, MA: Merriam-Webster.

Pacherie, E. (2006). Toward a dynamic theory of intentions. In S. Pockett, W. P. Banks \& S. Gallagher (Eds.), Does consciousness cause behavior? (pp. 145-167). Cambridge, MA: MIT Press.

Pacherie, E. (2008). The phenomenology of action: A conceptual framework. Cognition, 107(1), 179217.

Previc, F.H. (1998). The neuropsychology of 3-D space. Psychological Bulletin, 124(2), 123-164.

Riva, G. (2007). Virtual Reality and Telepresence. Science, 318(5854), 1240-1242.

Riva, G. (2008). Enacting Interactivity: The Role of Presence. In F. Morganti, A. Carassa \& G. Riva (Eds.), Enacting Intersubjectivity: A cognitive and social perspective on the study of interactions (pp. 97-114). Amsterdam: IOS Press: Online: http://www.emergingcommunication.com/ volume10.html.

Riva, G. (2009). Is presence a technology issue? Some insights from cognitive sciences Virtual Reality, 13(3), 59-69.

Riva, G. (2012). What is Positive Technology and its impact on CyberPsychology. Stud Health Technol Inform, 181, 37-41.

Riva, G., Banos, R. M., Botella, C., Wiederhold, B. K., \& Gaggioli, A. (2012). Positive technology: using interactive technologies to promote positive functioning. Cyberpsychology, behavior and social networking, 15(2), 69-77.

Riva, G., Davide, F., \& IJsselsteijn, W.A. (Eds.). (2003). Being There: Concepts, effects and measurements of user presence in synthetic environments. Amsterdam: los Press.

Riva, G., \& Mantovani, F. (2012). From the body to the tools and back: a general framework for presence in mediated interactions. Interacting with Computers, 24(4), 203-210.

Riva, G., Waterworth, J.A., \& Waterworth, E.L. (2004). The Layers of Presence: a bio-cultural approach to understanding presence in natural and mediated environments. Cyberpsychology \& Behavior, 7(4), 405-419.

Riva, G., Waterworth, J.A., Waterworth, E.L., \& Mantovani, F. (2011). From intention to action: The role of presence. New Ideas in Psychology, 29(1), 24-37.

Rizzolatti, G., Fadiga, L., Gallese, V., \& Fogassi, L. (1996). Premotor cortex and the recognition of motor actions. Cognitive Brain Research, 3, 131-141.

Rizzolatti, G., \& Sinigaglia, C. (2006). So quel che fai. Il cervello che agisce e i neuroni specchio. Milano: Raffaello Cortina.

Rosenblum, L. (2000). Virtual and Augmented Reality 2020. IEEE Computer Graphics and Applications, 20(1), 38-39. 
Slater, M., Perez-Marcos, D., Ehrsson, H. H., \& Sanchez-Vives, M. V. (2009). Inducing illusory ownership of a virtual body. Front Neurosci, 3(2), 214-220.

Slater, M., Spanlang, B., Sanchez-Vives, M. V., \& Blanke, O. (2010). First person experience of body transfer in virtual reality. PLoS One, 5(5), e10564.

Spagnolli, A., \& Gamberini, L. (2002, 9-11 October). Immersion/Emersion: Presence in hybrid environments. Paper presented at the Presence 2002: Fifth Annual International Workshop, Porto, Portugal.

Spagnolli, A., \& Gamberini, L. (2005). A Place for Presence. Understanding the Human Involvement in Mediated Interactive Environments. PsychNology Journal, 3(1), 6-15.

Waterworth, J.A., \& Waterworth, E.L. (2006). Presence as a Dimension of Communication: Context of Use and the Person. In G. Riva, M. T. Anguera, B. K. Wiederhold \& F. Mantovani (Eds.), From Communication to Presence: Cognition, Emotions and Culture towards the Ultimate Communicative Experience (pp. 80-95). Amsterdam: IOS Press.

Waterworth, J.A., Waterworth, E.L., Mantovani, F., \& Riva, G. (2010). On Feeling (the) Present: An evolutionary account of the sense of presence in physical and electronically-mediated environments. Journal of Consciousness Studies, 17(1-2), 167-178.

Waterworth, J.A., Waterworth, E.L., Mantovani, F., \& Riva, G. (2012). Special Issue: Presence and Interaction. Interacting with Computers, 24(4), 190-192.

Wilson, M., \& Knoblich, G. (2005). The case for motor involvement in perceiving conspecifics. Psychological Bulletin, 131(3), 460-473.

Wirth, Werner, Hartmann, Tilo, Bocking, Saskia, Vorderer, Peter, Klimmt, Christoph, Schramm, Holger, Jancke, Petra. (2007). A Process Model of the Formation of Spatial Presence Experiences. Media Psychology, 9(3), 493-525. 